\title{
The therapeutic effect of monocyte chemoattractant protein-I delivered by an electrospun scaffold for hyperglycemia and nephrotic disorders
}

\author{
This article was published in the following Dove Press journal: \\ International Journal of Nanomedicine \\ 17 February 2014 \\ Number of times this article has been viewed
}

Cai Yong',
Zhengxin Wangl,*
Xing Zhang
Xiaomin Shi'
Zhijia $\mathrm{Ni}^{\text {I }}$
Hong Fu'
Guoshan
Ding'
Zhiren Fu'
Hao Yin ${ }^{1,3}$
'Department of Surgery, Organ
Transplant Center, Shanghai
Changzheng Hospital, Second Military
Medical University, Shanghai, People's
Republic of China; ${ }^{2}$ Department
of Transplantation, First Affiliated
Hospital of Wenzhou Medical College,
Wenzhou, People's Republic of China;
'Department of Surgery, University of
Chicago, Chicago, IL, USA
*These authors contributed equally to
this article

Correspondence: Hao Yin

Department of Surgery, Shanghai

Changzheng Hospital, Second

Military Medical University,

415 Fengyang Road, Shanghai 200003,

People's Republic of China

Tel +86 2l 81885745

Email haoyin.sh@gmail.com

\begin{abstract}
Here, we investigated in diabetic mice the therapeutic effect of monocyte chemoattractant protein-1 (MCP-1), locally delivered by an electrospun scaffold, on transplanted islets. This therapeutic scheme is expected to exert a synergistic effect to ameliorate hyperglycemia and its associated nephrotic disorders. The cumulative amount of MCP-1 released from the scaffold in vitro within a 3 -week window was $267.77 \pm 32.18 \mathrm{ng}$, without a compromise in bioactivity. After 8 weeks following the transplantation, the islet population stimulated by MCP-1 was $35.14 \% \pm 7.23 \%$ larger than the non-stimulated islet population. Moreover, MCP-1 increased concentrations of blood insulin and C-peptide 2 by $49.83 \% \pm 5.29 \%$ and $43.49 \% \pm 9.21 \%$, respectively. Consequently, the blood glucose concentration in the MCP-1 group was significantly lower than that in the control group at week 2 post-surgery. MCP-1 also enhanced the tolerance of sudden oral glucose challenge. The rapid decrease of blood creatinine, urine creatinine, and blood urea nitrogen suggested that the recovery of renal functions compromised by hyperglycemia could also be attributed to MCP-1. Our study shed new light on a synergistic strategy to alleviate hyperglycemia and nephrotic disorders in diabetic patients.
\end{abstract}

Keywords: MCP-1, electrospinning, islet transplantation, diabetes

\section{Introduction}

Despite decades of scientific endeavor, diabetes has remained a leading disease in the US that inflicts millions of patients. ${ }^{1}$ Moreover, chronic diabetes is believed to be the culprit for several other illnesses. ${ }^{2}$ For example, diabetes frequently compromises renal function, prompting a need for kidney transplantation. ${ }^{3}$ To that end, a comprehensive strategy to combat diabetes as well as its complications is in urgent need. In type I diabetes, pancreatic $\beta$-cells are destructed by abnormal autoimmunity, leading to the loss of insulin secretion and consequently to hyperglycemia. ${ }^{4}$ To clinically recoup the lost capability of insulin production, islet transplantation has been widely used but suffers mixed outcomes of therapeutic effectiveness. ${ }^{5}$ In conventional transplantation surgery, harvested islets are freely injected into the intrarenal capsule and start to secrete insulin thereafter. Clinical observations have revealed that a number of challenges have been associated with this means of islet transplantation. ${ }^{6}$ For example, despite limited availability of islets, the poor survival rate mandates that a large population of islets must be pooled from multiple donors. ${ }^{7}$ A number of factors could account for the poor survival rate after islet transplantation, such as local inflammation. ${ }^{8,9}$ 
Tissue engineering scientists have made tremendous progress on rebuilding a great variety of functional tissues using a wide range of biomaterials and nanofabrication technology. ${ }^{10-15}$ In light of previous research, we successfully developed an electrospun scaffold-assisted delivery of islets to enhance the control of hyperglycemia and associated nephrotic disorders in diabetic mice. ${ }^{16}$ The study demonstrated that the islet population in the scaffold-assisted delivery group outgrew its peer in the freely injected delivery group as early as week 4 after surgery, and sustained this advantage through week 12. Consequently, functional readouts such as insulin secretion saw an unequivocal improvement, which effectively drove down the blood glucose level in diabetic mice. In addition, boosted functional outputs of transplanted islets arrested the spiral deterioration of renal functions, as evidenced by a suppressed level of creatinine in both blood and urine samples. Monocyte chemoattractant protein-1 (MCP-1), a prominent immunomodulatory protein, has garnered a growing interest in the tissue engineering community, in that it plays a regulatory role in a variety of tissue regenerations. ${ }^{17-21}$ Previous research suggests that MCP-1 sees a temporary spike in local tissues after islet transplantation and that it helps to recoup compromised renal functions lost to hyperglycemia. ${ }^{16,22}$ In particular, recent findings suggest that local MCP-1 in islets can engage the immune system by targeting dendritic cells and, potentially, T-cells to inhibit diabetes. ${ }^{23}$ Therefore, these findings prompted us to hypothesize that local stimulation of islets and renal tissues by MCP-1 released from a scaffold would exert a synergistic effect on alleviating hyperglycemia and associated nephrotic disorders in diabetic mice. In this study, we engineered a drug-eluting electrospun scaffold composed of polycaprolactone (PCL) and poliglecaprone (PGC) to locally deliver MCP-1.

\section{Methods}

\section{The fabrication and morphological characterizations of electrospun scaffolds}

The scaffold was electrospun as previously described. ${ }^{16}$ Briefly, PGC (Advanced Inventory Management, Mokena, IL, USA) and PCL (Absorbable Polymers, Birmingham, AL, USA) were used as received. Both polymers were dissolved in 1,1,1,3,3,3-hexafluoro-2-propanol (Sigma-Aldrich, St Louis, MO,USA) to achieve a total concentration of $12 \%$ (weight/volume $[\mathrm{w} / \mathrm{v}]$ ) (weight ratio of 1:3). For drug-eluting scaffolds (DESs), recombinant MCP-1 (Peprotech, Rocky Hill, NJ, USA) was added to the dissolved polymer solution $(2 \mu \mathrm{g} / \mathrm{mL})$. Then, $0.5 \mathrm{~mL}$ of the solution was electrospun at a feeding rate of $3 \mathrm{~mL} /$ hour to a collection board distanced at $25 \mathrm{~cm}$ at a voltage of $30 \mathrm{kV}$. Retrieved scaffolds were desiccated in vacuum for 24 hours. For non-eluting scaffolds (NESs), the solution absent of MCP-1 was electrospun under the same conditions. Scaffold samples $(1 \mathrm{~cm} \times 1 \mathrm{~cm})$ were sputter-coated by gold and studied using a scanning electron microscope.

\section{In vitro pharmacokinetic study of MCP-I release}

To study the release profile of MCP-1 from the scaffold, DESs (diameter $=1.6 \mathrm{~cm}$ ) were incubated in Prigrow II medium supplemented with heat-inactivated fetal bovine serum to a final concentration of $10 \%$ and penicillin/streptomycin (Applied Biological Materials Inc., Richmond, BC, Canada) at $37^{\circ} \mathrm{C}$ and $5 \% \mathrm{CO}_{2}$ for up to 3 weeks. The supernatant was collected every week for enzyme-linked immunosorbent assay (ELISA) assay (R\&D Systems, Minneapolis, MN, USA) per manufacturer's protocol. NESs were incubated under the same conditions as a control.

To assess the bioactivity of released MCP-1, a chemotaxis assay was performed (EMD Millipore, Billerica, MA, USA) per manufacturer's protocol. Human CD14+ monocytes (Applied Biological Materials) were seeded into each migration chamber $\left(1 \times 10^{5}\right.$ cells $/$ chamber $)$. The supernatant from the medium in which DESs or NESs had been incubated for 3 weeks was used for samples. Medium containing MCP-1 $(2 \mu \mathrm{g} / \mathrm{mL})$ was used as positive control, and medium without MCP-1, as negative control.

\section{The creation of mouse insulin I promoter-luciferase (MIP-luc) transgenic mice and the islet transplantation}

Shanghai Changzheng Hospital approved the animal study protocol, and ensured the animal welfare throughout the study. The MIP-luc transgenic mice (in a C57BL/6 background) whose transgene contained an MIP promoter fragment leading to the expression of the firefly luciferase (MIP-luc) were generated as reported before. ${ }^{24,25}$ Previous research demonstrated that $\beta$-cells from MIP-luc mice can be visualized using bioluminescent imaging, and their mass is correlated with the bioluminescent signal. ${ }^{26}$ Each hemizygous MIPluc transgenic mouse received one dose of streptozotocin (50 mg/kg; Sigma Aldrich, St Louis, MO, USA) by intraperitoneal injection every 2 days for a total of five doses. The dosage was based on previous study ${ }^{16}$ to induce diabetes and a gradual renal deterioration before the islet transplantation. Mice were considered diabetic if the blood glucose concentration exceeded $400 \mathrm{mg} / \mathrm{dL}$ for more than two consecutive days without fasting. DESs and NESs $(1 \mathrm{~mm} \times 1 \mathrm{~mm})$ were 
sterilized in $70 \%$ ethanol followed by an extensive rinse in sterile phosphate buffered saline. Harvested islets were seeded on respective scaffolds (100 islet equivalents/scaffold) and incubated for 3 hours at $37^{\circ} \mathrm{C}$ with $5 \% \mathrm{CO}_{2}$ prior to the surgery. All mice were anesthetized by vaporized $2.5 \%$ isoflurane via inhalation. Islets on respective scaffolds were surgically placed under the kidney capsule. All mice were sacrificed 8 weeks after the surgery.

\section{The in vivo growth of transplanted islets}

Xenogen IVIS 200 imaging system (Xenogen Corporation, Alameda, CA, USA) was used to capture bioluminescent optical images as previously described. ${ }^{24}$ Briefly, after a 4-hour fast, MIP-luc mice were anesthetized with vaporized isoflurane. Mice were positioned on their sides on the imaging stage to capture an initial image. Each mouse then received $15 \mathrm{mg} / \mathrm{mL}$ D-luciferin in sterile phosphate buffered saline $(150 \mathrm{mg} / \mathrm{kg})$ via intraperitoneal injection, and a bioluminescent image was captured (exposure time $=1 \mathrm{~min}$ ) at 14 minutes post-injection. Image processing and quantification of bioluminescence were carried out using Living Image $^{\circledR}$ (Xenogen Corporation) software, version 2.05.

\section{Measurements of blood insulin, C-peptide 2, blood glucose, and oral glucose tolerance test}

Each mouse underwent a blood withdrawal from the tail vein immediately before the surgery (week 0 ) and then on weeks 2,4 , and 8 post-surgery before the euthanasia. No fasting was imposed before blood withdrawals. A rat insulin ELISA kit with mouse insulin standards (Crystal Chem Inc., Chicago, IL, USA) and serum C-peptide 2 assayed with a rat/mouse C-peptide 2 ELISA kit (EMD Millipore) were used to measure the insulin and C-peptide 2 levels as per manufacturers' protocols. Blood glucose was measured by OneTouch $^{\circledR}$ Ultra $^{\circledR}$ (LifeScan/Johnson and Johnson, Milpitas, CA, USA) glucometer. The oral glucose tolerance test (OGTT) was carried out 8 weeks after the surgery. After a 16-hour fast, blood samples were collected from the tail vein as the baseline glucose level (0 minutes). Thereafter, the glucose solution in sterile water $(100 \mathrm{mg} / \mathrm{mL})$ (Sigma-Aldrich) was administered to each mouse by oral gavage $(2 \mathrm{~g} / \mathrm{kg})$. Blood glucose levels were measured in blood samples collected at 30,60 , and 120 minutes after the glucose challenge, as described above.

\section{The evaluation of renal function following the islet transplantation}

Blood and urine samples were collected immediately before the implantation (week 0) and on weeks 2, 4, and 8 after the surgery. Blood creatinine (Abcam, Cambridge, MA, USA), blood urea nitrogen (Bio Scientific Corp, Austin, TX, USA), urine creatinine (Abcam), and urine albumin (Abnova, Walnut, CA, USA) were assayed following manufacturers' protocols.

\section{Data analysis}

Student's $t$-test and analysis of variance were used where applicable $(\alpha=0.05)$. Images were processed with ImageJ (National Institutes of Health, Bethesda, MD, USA) software.

\section{Results}

\section{Physical characterizations of scaffolds}

Electrospun scaffolds composed of various polymers and/ or proteins have been extensively explored as drug-delivery vehicles for tissue engineering purposes. ${ }^{27-29}$ In light of previous research, we here successfully constructed DESs carrying MCP-1 for local delivery. Both DESs and NESs demonstrated a highly porous microstructure composed of randomly distributed fibers on the microscale (Figure 1).

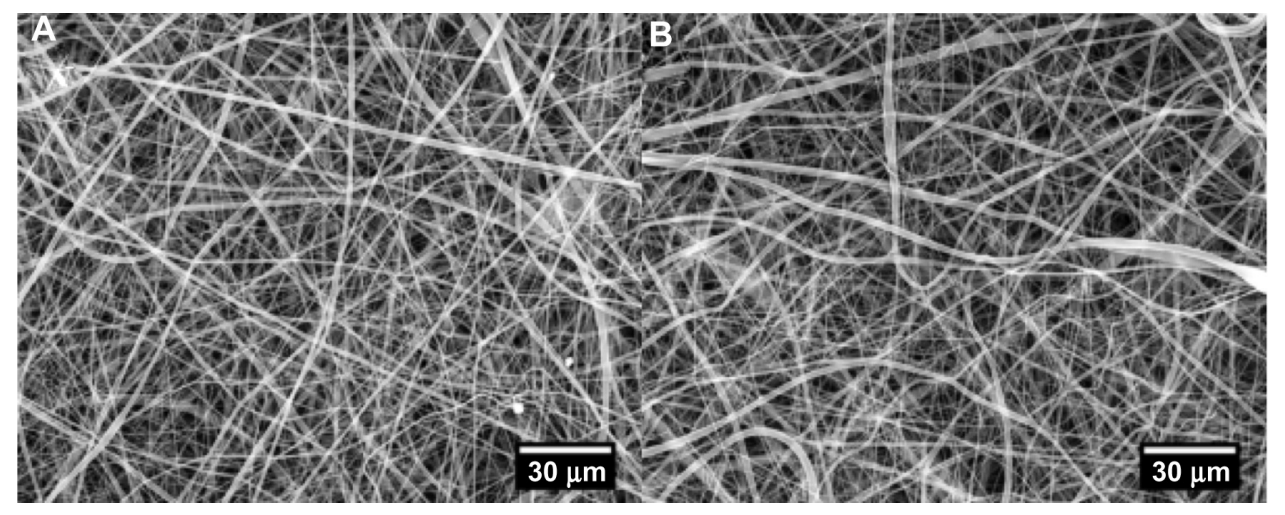

Figure I The morphological characterization of non-eluting scaffolds (A) and MCP-I drug-eluting scaffolds (B) by scanning electron microscope. The introduction of MCP-I into the scaffold did not cause a morphological change of electrospun fibers.

Abbreviation: MCP-I, monocyte chemoattractant protein-I. 
No morphological difference was observed between the two scaffolds, suggesting that the incorporation of MCP-1 did not lead to a structural change. This lack of morphological change would rule out the possibility that the difference of biological readouts came from changes of environmental cues conferred on transplanted islets. The MCP-1 from DESs witnessed a rapid release within the first week and a reduced momentum in the next 2 weeks (Figure 2A). By the end of week 3, the DES had released a total of $267.77 \pm 32.18 \mathrm{ng}$ MCP-1 into the medium, while no MCP-1 was detected in the NES group. Also, MCP-1 released from the scaffold retained its bioactivity (Figure $2 \mathrm{~B}$ ). This rapid release in the first week would be beneficial for the overall success of islet transplantation because it would quickly elevate the local MCP-1 concentrations for a maximal therapeutic effect. The sustained release through week 3 ensured that local tissues would consistently be stimulated by MCP-1 from the DES scaffold. Thereafter, local tissues are expected to compensate the exhausted MCP-1 from DESs as an immunological consequence of the islet transplantation. ${ }^{22}$

\section{The in vivo growth of transplanted islets}

Prior research demonstrated that the strength of the bioluminescent signal is positively associated with the mass of transplanted islets, establishing that it was a quantitative and noninvasive way to measure the islet proliferation. ${ }^{24}$ Previously, we demonstrated NESs provide a more favorable microenvironment that ultimately translates into an accelerated proliferation than freely injected islets. ${ }^{16}$ To that end, in this study, we specifically focused on whether MCP-1 released from the DESs could further enhance the proliferation of islets than that released from NES. The islet population in the DES group started to outgrow its peer in the NES group as early as week four and maintained this proliferative advantage through week 8 (Figure 3). At week 4, the bioluminescent signal strength of the islet population in the DES group was $(38.73 \pm 2.82) \times 10^{3}$ photons/second, whereas the strength in the NES group was $(29.35 \pm 3.01) \times 10^{3}$ photons/second. At week eight, the strength in the DES group grew to $(40.89 \pm 3.35) \times 10^{3}$ photons/second, whereas that in the NES group was $(30.26 \pm 2.99) \times 10^{3}$ photons/second. The islet population in the DES group was significantly larger at both week $4(P=0.0078)$ and week 8 $(P=0.0102)$. However, no difference was observed between the two groups at week 2 . These results suggested that the local delivery of MCP-1 might not have translated into a marked increase of islet proliferation in the initial stage but might have contributed to the long-term proliferation.

\section{The functional outputs of transplanted islets}

Both blood insulin and C-peptide 2 concentrations saw a sustained difference between the DES and NES groups from week 2 after the surgery (Figure 4). The insulin concentrations in the DES and NES groups were $272.34 \pm 38.94 \mathrm{pg} / \mathrm{mL}$ and $173.45 \pm 37.21 \mathrm{pg} / \mathrm{mL}$, respectively, at week 2 . By week 8 , the insulin concentrations were $377.91 \pm 49.34 \mathrm{pg} / \mathrm{mL}$ in the DES group and $252.22 \pm 40.11 \mathrm{pg} / \mathrm{mL}$ in the NES group. Correspondingly, the C-peptide 2 concentrations were $49.23 \pm 6.97 \mathrm{pM}$ in the DES group and $32.11 \pm 4.56 \mathrm{pM}$ in the NES group at week 2 . By week 8 , the C-peptide 2 concentrations were $69.29 \pm 6.82 \mathrm{pM}$ in the DES group and $48.29 \pm 8.22$ $\mathrm{pM}$ in the NES group.

At week 2, the blood glucose levels were $228 \pm 31 \mathrm{mg} / \mathrm{dL}$ in the DES group and $321 \pm 37 \mathrm{mg} / \mathrm{dL}$ in the NES group, showing a significant difference $(P=0.0098)$ (Figure 5A). However, this difference disappeared by week 4 , when the blood glucose levels in both groups fell into the physiological range. On the other hand, the OGTT result clearly showed

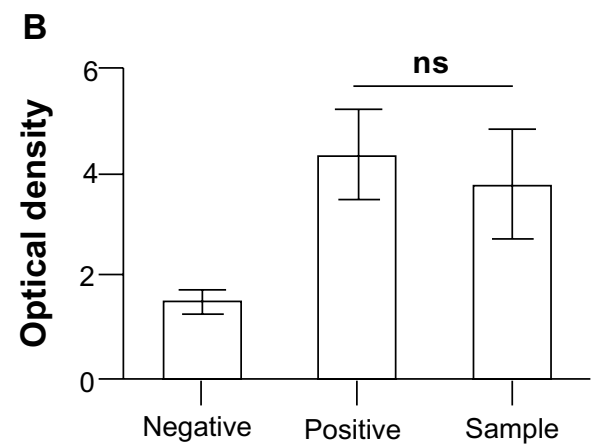

Figure 2 (A) The in vitro cumulative release of MCP-I from DES. (B) The bioactivity of released MCP-I. The DES saw a rapid unleash of MCP-I in the first week and then a steadfast release through week 3. No MCP-I was detected in the NES group. MCP-I retained its bioactivity throughout the delivery.

Notes: Negative = cell medium without MCP-I; positive = cell medium with MCP-I $(2 \mu \mathrm{g} / \mathrm{mL})$; sample = supernatant containing released MCP-I at week 3 ( $\mathrm{n}=3)$.

Abbreviations: DES, drug-eluting scaffold; MCP-I, monocyte chemoattractant protein-I; NES, non-eluting scaffold; ns, not significant. 


\section{A}

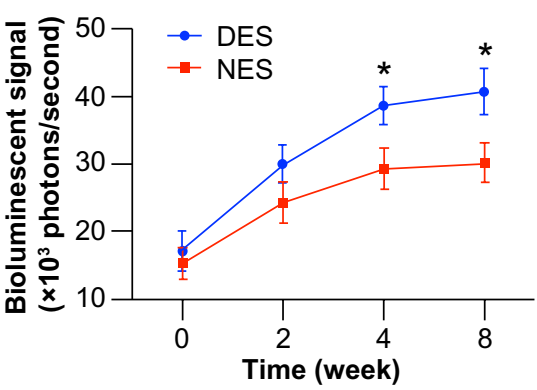

B

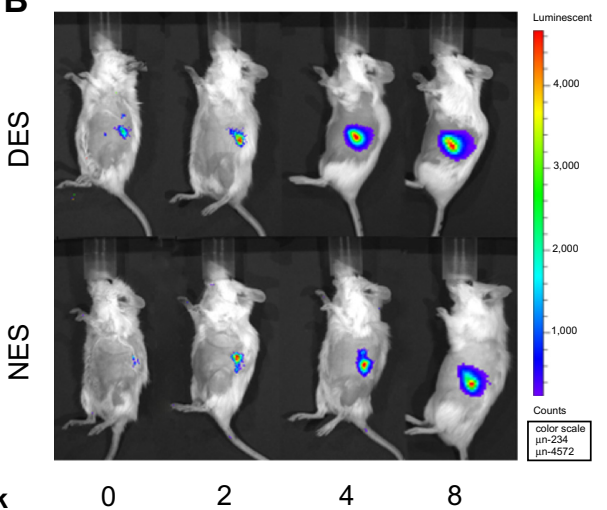

Figure 3 (A) The quantification of bioluminescent signals. (B) Representative bioluminescent images. The islet population in the DES group outgrew its peer in the NES group at week 4 . This proliferative advantage was further pronounced at week 8.

Note: *Statistical difference between the groups ( $n=7$ in the DES group; $n=6$ in the NES group).

Abbreviations: DES, drug-eluting scaffold; NES, non-eluting scaffold.

that mice in the DES group possessed a stronger capability to tolerate glucose challenge (Figure 5B). At 30 minutes after the oral gavage, blood glucose levels in mice from the DES and NES groups were $352 \pm 35 \mathrm{mg} / \mathrm{dL}$ and $475 \pm 58 \mathrm{mg} / \mathrm{dL}$, respectively, showing a significant difference $(P=0.0012)$.

The blood glucose level in mice from the DES group was consistently lower than that in the NES group throughout the 120-minute period. These results substantiated that the increased insulin production due to the stimulation of MCP-1 from DESs successfully translated into an accelerated return of blood glucose levels into the physiological range and a greater capacity to withstand sudden glucose challenges.

\section{Renal protein concentrations after the islet transplantation}

A significant difference of blood creatinine, urine creatinine, and blood urea nitrogen concentrations were observed between the DES and NES groups at week 2. Specifically, the blood creatinine concentrations were $0.94 \pm 0.15 \mathrm{mg} / \mathrm{dL}$ in the DES group and $1.56 \pm 0.15 \mathrm{mg} / \mathrm{dL}$ in the NES group (Figure 6A). The urine creatinine concentrations were $145 \pm 12 \mathrm{mg} / \mathrm{dL}$ in the DES group and $178 \pm 13 \mathrm{mg} / \mathrm{dL}$ in the NES group (Figure 6B). The blood urea nitrogen concentrations were $47 \pm 9 \mathrm{mg} / \mathrm{dL}$ in the DES group and $67 \pm 8 \mathrm{mg} / \mathrm{dL}$ in the NES group (Figure 7A). However, no difference in urine albumin was observed between the two groups (Figure 7B). These results suggest that $\mathrm{MCP}-1$ accelerated the recovery of renal functions following the local delivery. The disappearance of a difference by week 4 could be attributed to the exhausted source of MCP-1 in the DESs and the increased MCP-1 secretion by local renal tissues in response to the islet transplantation.

\section{Discussion}

The tissue-engineered microenvironment could exert a profound influence on individual cells and their functions. ${ }^{30-32}$
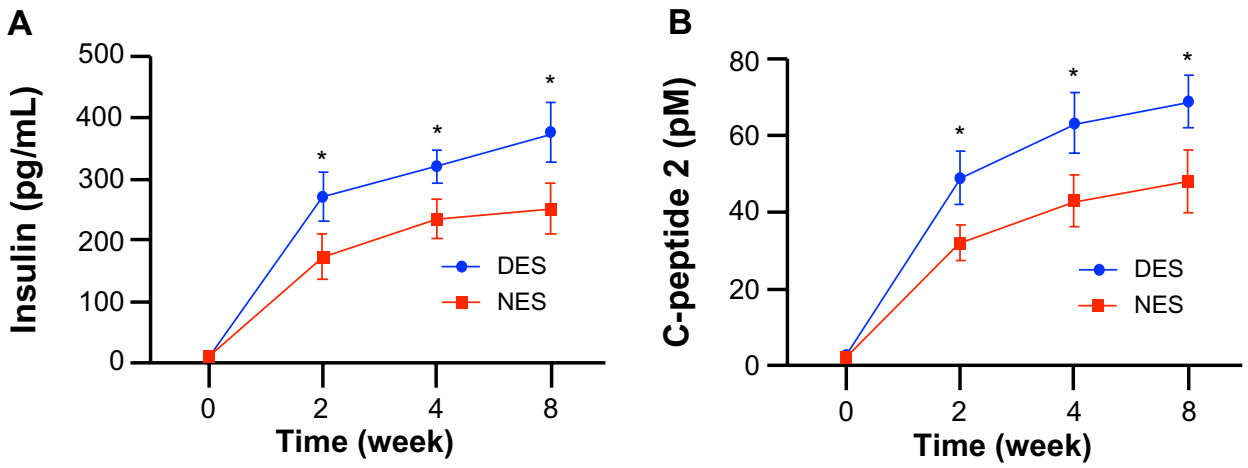

Figure 4 Functional outputs of transplanted islets: (A) blood insulin concentrations; and (B) C-peptide 2 concentrations. The insulin level in the DES group outperformed the NES group as early as week 2 and maintained this advantage through week 8 . A correlated advantage of C-peptide 2 was observed.

Note: *Statistical difference between the groups ( $n=7$ in the DES group; $n=6$ in the NES group).

Abbreviations: DES, drug-eluting scaffold; NES, non-eluting scaffold. 

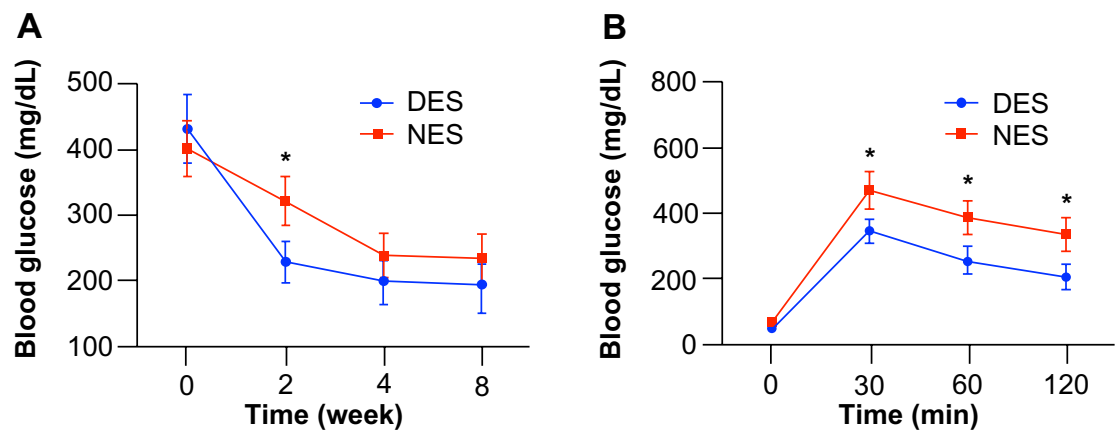

Figure 5 Blood glucose concentrations after the islet transplantation: blood glucose levels (A) and oral glucose tolerance test (B) at week 8 . The blood glucose in the DES group returned to the physiological range as early as week 2, outpacing its peer from the NES group. Correspondingly, islet transplants in the DES group unleashed a greater resistance to sudden glucose challenge, evidencing the improved therapeutic effect of DESs.

Note: *Statistical difference between the groups ( $n=7$ in the DES group; $n=6$ in the NES group).

Abbreviations: DES, drug-eluting scaffold; NES, non-eluting scaffold.

In our research, this tissue-engineered scaffold was supposed to confer a favorable microenvironment for islet cells to adhere, proliferate, and ultimately produce insulin to rein in the hyperglycemia. In previous research, we demonstrated that the NES increased the islet proliferation and insulin production in vitro with no cytotoxic effects observed, suggesting that the degradation of scaffolding materials posed no threat to the population. ${ }^{16}$ The lack of morphological change of fibers in DESs guaranteed that the optimal performance attained by NESs in previous research would not be compromised.

It should be noted that tissue engineered scaffolds are supposed to degrade over time to allow the growth of native tissues and the deposition of native extracellular matrix. ${ }^{33-35}$ Both PGC and PCL are widely used biodegradable suture materials for various tissue-engineering purposes, without cytotoxicity, and both demonstrated an excellent in vivo biocompatibility to promote the growth and functional output of transplanted islets. ${ }^{10-16}$

To further enhance the therapeutic effect of our electrospun scaffold, we focused an investigative spotlight on
MCP-1 in this study. MCP-1 is an immunomodulating factor that mediates a wide range of biological events, ranging from the regeneration of vascular tissues to local inflammation in renal tissues in diabetic patients. ${ }^{17,19}$ Prior research has even proposed that the level of MCP-1 be used as a clinical indicator of renal inflammation caused by diabetes. ${ }^{36-38}$

Interestingly, a recent study discovered that local MCP-1 was able to inhibit diabetes, possibly by engaging dendritic cells and T-cells in islets, although the exact underlying mechanism remains elusive. ${ }^{23}$ A rapid release of MCP-1 is believed to contribute to the acceleration of the therapeutic regeneration of diseased or injured tissues and angiogenesis. ${ }^{39,40}$ However, previous research suggests that a prolonged high level of inflammation is detrimental to the tissue regeneration and functional recovery. ${ }^{37,38}$ Therefore, a rapid yet temporary release of $\mathrm{MCP}-1$ from the DES might be a desired scheme to kick start the functional recovery of local tissues without causing unnecessary stress. It should be noted that administered MCP-1 is rapidly distributed to various organs and injured tissues, and features a transient
A

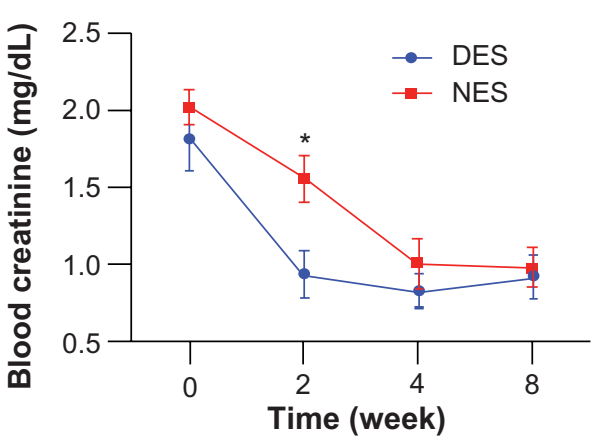

B

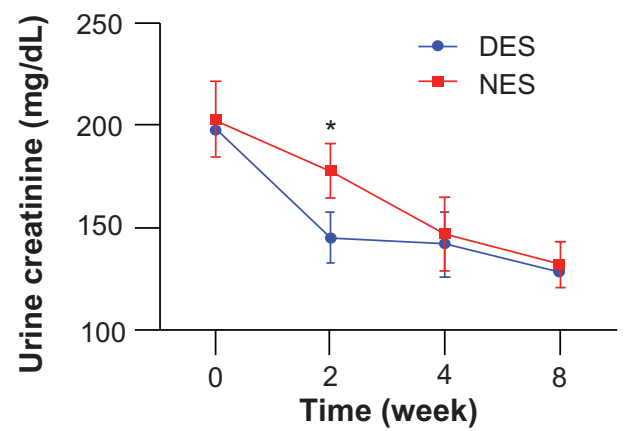

Figure 6 Creatinine levels in blood $(\mathbf{A})$ and urine (B). The concentrations of blood creatinine and urine creatinine in the DES group fell to the physiological range by week 2 , while those from the NES group were still abnormally high.

Note: *Statistical difference between the groups ( $n=7$ in the DES group; $n=6$ in the NES group).

Abbreviations: DES, drug-eluting scaffold; NES, non-eluting scaffold. 
A

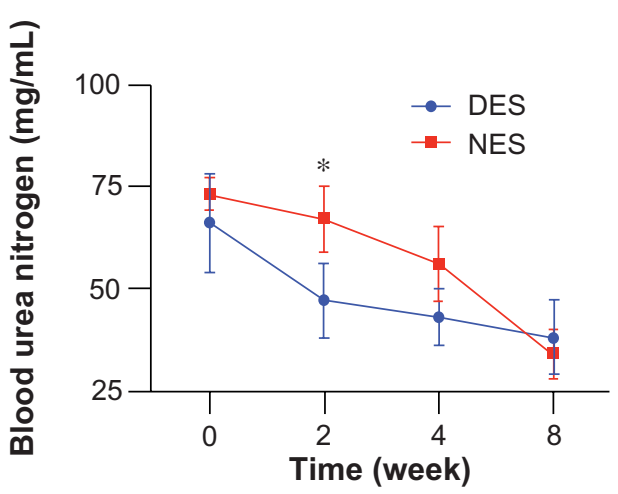

B

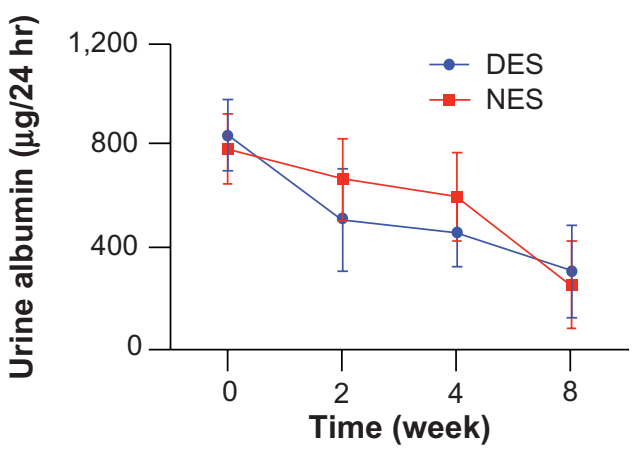

Figure 7 Blood urea nitrogen $(\mathbf{A})$ and urine albumin $(\mathbf{B})$ levels. The concentration of blood urea nitrogen in the DES group was reduced to the physiological range by week 2 , while no difference of urine albumin concentrations between DES and NES groups was observed. Note: *Statistical difference between the groups ( $n=7$ in the DES group; $n=6$ in the NES group). Abbreviations: DES, drug-eluting scaffold; NES, non-eluting scaffold.

half-life in blood circulation. ${ }^{40}$ Also, MCP-1 is produced by a variety of tissues under both physiological and pathological conditions, rendering it impossible to discriminate native MCP-1 from the administered one. ${ }^{41,42}$

A satisfactory recovery of insulin secretion is a critical benchmark for the success of this bioengineering strategy, because it would return the blood glucose concentration to a physiological level, thus relieving other organs from the biological stress caused by hyperglycemia. The injection of insulin into diabetic patients to control the blood glucose level has been a popular clinical therapy. But, unfortunately, it could cause a variety of complications, including hypoglycemia, hyperglycemia, and seizure. To that end, the reestablishment of an in vivo native-like biological insulin-production mechanism through islet transplantation was developed. In this therapeutic scheme, C-peptide, a byproduct with no known functions during the native production of insulin by the pancreas, is an important and convenient clinical indicator of the production of endogenous insulin. Consequently, a correlated presence of $\mathrm{C}$-peptide evidences the therapeutic effectiveness of transplanted islets. The results that both insulin and C-peptide 2 levels in the DES group were higher than those in the NES group at week 2 suggests that DESs enhanced the functional output of transplanted islets and thus would potentially improve the overall therapeutic effectiveness of the islet transplantation.

Consistent hyperglycemia is the culprit for the various complications in diabetic patients, particularly the loss of renal functions. ${ }^{43}$ So an effective management of blood glucose is critical to rescue failing kidneys in diabetic patients. In our previous research, we showed that the improved islet functions due to the use of scaffolds helped to rein in blood glucose level faster than the traditional means of islet transplantation. ${ }^{16}$ In the present study, we demonstrated that the incorporation of MCP-1 into the scaffold could further pronounce this advantage in regulating blood glucose. The OGTT result spoke to the fact that transplanted islets possessed a stronger blood glucose regulatory capacity in the face of a sudden spike of blood glucose, evidencing the long-term benefits afforded by the DES.

According to American Diabetes Association, diabetic patients who suffer failing kidneys frequently undergo kidney transplantation to recoup critical renal functions. Unfortunately, kidneys are extremely limited at best, and out of sight at worst. For the cohort of diabetic patients, an alternative strategy to simultaneously restore insulin production and renal functions is of great significance. Our previous research showed that blood MCP-1 level spiked after islet transplantation, probably due to enhanced immune response to the transplanted islets. ${ }^{16}$ In that study, the spike of the MCP-1 level correlated to improved functional outputs of transplanted islets and renal tissues, which prompted us to further investigate the therapeutic role of MCP-1 in renal functions in diabetes. We later discovered that MCP-1 via intraperitoneal injection would accelerate the recovery of renal functions compromised by diabetes. The half-life of injected MCP-1 in the blood circulation was extremely short because MCP-1 would rapidly accumulate into various organs, which might explain the late onset of therapeutic effect. ${ }^{40}$ In addition, the fact that cells in various tissues could secrete MCP-1 further complicates the task to tease out the relationship between $\mathrm{MCP}-1$ and renal function recovery in a diabetic context. ${ }^{41,43}$ These challenges prompted us to functionalize the scaffold to locally deliver MCP-1 in the hope of 
enhancing the therapeutic effect. We found that MCP-1 from DESs accelerated the recapitulation of renal functions, but this advantage would soon diminish. This phenomenon might be attributed to the activation of a native immunoregulatory mechanism, because an artificially increased level of MCP-1 would induce an overwhelming immune response that might be detrimental to a functional recovery. All of the four renal proteins returning to physiological range demonstrated that the DESs accelerated renal function recovery without introducing cytotoxic effects.

Islet transplantation is currently the gold standard clinical solution to recoup lost insulin secretion in diabetic patients. We previously proved that the employment of an electrospun scaffold could promote the islet proliferation and functional output, in particular, the insulin secretion. In addition, we discovered an active role of MCP-1 in recouping renal functions lost to diabetes. ${ }^{16}$ In this present study, we further explored a synergistic strategy to simultaneously enhance the functional output of transplanted islets as well as the recovery of renal functions. Our results confirmed that the local delivery of MCP-1 from a DES enhanced the insulin secretion of transplanted islets despite islet proliferation being only moderately increased. This increased insulin secretion successfully drove down the blood glucose to the physiological range within 2 weeks. Moreover, renal functions were swiftly recouped within 2 weeks. These increased functions could be attributed to the local stimulation of MCP-1. Our study offered a synergistic bioengineering strategy to simultaneously manage blood glucose and recoup compromised renal functions due to hyperglycemia.

\section{Acknowledgment}

The authors are grateful for the financial support from China's National Natural Science Foundation (Grant Numbers: 30300357, 81270550 and 81270551).

\section{Disclosure}

The authors report no conflicts of interest in this work.

\section{References}

1. Gregg EW, Cheng YJ, Saydah S, et al. Trends in death rates among US adults with and without diabetes between 1997 and 2006: findings from the National Health Interview Survey. Diabetes Care. 2012;35(6): $1252-1257$.

2. Porte D Jr, Schwartz MW. Diabetes complications: why is glucose potentially toxic? Science. 1996;272(5262):699-700.

3. Gackler D, Jakel S, Fricke L, Reinsch B, Fischer F. [Diabetes and kidneys]. Dtsch Med Wochenschr. 2013;138(18):949-955. German.

4. Mathis D, Vence L, Benoist C. Beta-cell death during progression to diabetes. Nature. 2001;414(6865):792-798.

5. Ryan EA, Lakey JR, Paty BW, et al. Successful islet transplantation: continued insulin reserve provides long-term glycemic control. Diabetes. 2002;51(7):2148-2157.
6. Robertson RP. Islet transplantation as a treatment for diabetes - a work in progress. N Engl J Med. 2004;350(7):694-705.

7. Ricordi C, Strom TB. Clinical islet transplantation: advances and immunological challenges. Nat Rev Immunol. 2004;4(4):259-268.

8. Jaeger C, Brendel MD, Hering BJ, Eckhard M, Bretzel RG. Progressive islet graft failure occurs significantly earlier in autoantibody-positive than in autoantibody-negative IDDM recipients of intrahepatic islet allografts. Diabetes. 1997;46(11):1907-1910.

9. Barshes NR, Wyllie S, Goss JA. Inflammation-mediated dysfunction and apoptosis in pancreatic islet transplantation: implications for intrahepatic grafts. J Leukoc Biol. 2005;77(5):587-597.

10. Zhang X, Xu Y, Thomas V, Bellis SL, Vohra YK. Engineering an antiplatelet adhesion layer on an electrospun scaffold using porcine endothelial progenitor cells. J Biomed Mater Res A. 2011;97(2): $145-151$.

11. Zhang X, Thomas V, Xu Y, Bellis SL, Vohra YK. An in vitro regenerated functional human endothelium on a nanofibrous electrospun scaffold. Biomaterials. 2010;31(15):4376-4381.

12. Zhang X, Thomas V, Vohra YK. Two ply tubular scaffolds comprised of proteins/poliglecaprone/polycaprolactone fibers. J Mater Sci Mater Med. 2010;21(2):541-549.

13. Thomas V, Zhang X, Vohra YK. A biomimetic tubular scaffold with spatially designed nanofibers of protein/PDS bio-blends. Biotechnol Bioeng. 2009;104(5):1025-1033.

14. Zhang X, Thomas V, Vohra YK. In vitro biodegradation of designed tubular scaffolds of electrospun protein/polyglyconate blend fibers. J Biomed Mater Res B Appl Biomater. 2009;89(1):135-147.

15. Thomas V, Zhang X, Catledge SA, Vohra YK. Functionally graded electrospun scaffolds with tunable mechanical properties for vascular tissue regeneration. Biomed Mater. 2007;2(4):224-232.

16. Yin H, Gao M, Leoni L, Han H, Zhang X, Fu Z. The therapeutic role of monocyte chemoattractant protein-1 in a renal tissue engineering strategy for diabetic patients. PloS One. 2013;8(2):e57635.

17. Panee J. Monocyte chemoattractant protein 1 (MCP-1) in obesity and diabetes. Cytokine. 2012;60(1):1-12.

18. Park S, Lakatta EG. Role of inflammation in the pathogenesis of arterial stiffness. Yonsei Med J. 2012;53(2):258-261.

19. Schober A. Chemokines in vascular dysfunction and remodeling. Arterioscler Thromb Vasc Biol. 2008;28(11):1950-1959.

20. Gillitzer R, Goebeler M. Chemokines in cutaneous wound healing. J Leukoc Biol. 2001;69(4):513-521.

21. Graves DT, Jiang Y, Valente AJ. The expression of monocyte chemoattractant protein-1 and other chemokines by osteoblasts. Front Biosci. 1999;4:D571-D580.

22. Piemonti L, Leone BE, Nano R, et al. Human pancreatic islets produce and secrete MCP-1/CCL2: relevance in human islet transplantation. Diabetes. 2002;51(1):55-65.

23. Kriegel MA, Rathinam C, Flavell RA. Pancreatic islet expression of chemokine CCL2 suppresses autoimmune diabetes via tolerogenic CD11c+ CD11b+ dendritic cells. Proc Natl Acad Sci U S A. 2012;109(9):3457-3462.

24. Park SY, Wang X, Chen Z, et al. Optical imaging of pancreatic beta cells in living mice expressing a mouse insulin I promoter-firefly luciferase transgene. Genesis. 2005;43(2):80-86.

25. Hara M, Wang X, Kawamura T, et al. Transgenic mice with green fluorescent protein-labeled pancreatic beta-cells. Am J Physiol Endocrinol Metab. 2003;284(1):E177-E183.

26. Grossman EJ, Lee DD, Tao J, et al. Glycemic control promotes pancreatic beta-cell regeneration in streptozotocin-induced diabetic mice. PloS One. 2010;5(1):e8749.

27. Meinel AJ, Germershaus O, Luhmann T, Merkle HP, Meinel L. Electrospun matrices for localized drug delivery: current technologies and selected biomedical applications. Eur J Pharm Biopharm. 2012;81(1):1-13.

28. Ji W, Sun Y, Yang F, et al. Bioactive electrospun scaffolds delivering growth factors and genes for tissue engineering applications. Pharm Res. 2011;28(6):1259-1272. 
29. Sill TJ, von Recum HA. Electrospinning: applications in drug delivery and tissue engineering. Biomaterials. 2008;29(13):1989-2006.

30. Tibbitt MW, Anseth KS. Dynamic microenvironments: the fourth dimension. Sci Transl Med. 2012;4(160):160ps24.

31. Prewitz M, Seib FP, Pompe T, Werner C. Polymeric biomaterials for stem cell bioengineering. Macromol Rapid Commun. 2012;33(17): 1420-1431.

32. Baker BM, Chen CS. Deconstructing the third dimension: how 3D culture microenvironments alter cellular cues. J Cell Sci. 2012;125(Pt 13): 3015-3024.

33. Yannas IV. Emerging rules for inducing organ regeneration. Biomaterials. 2013;34(2):321-330.

34. Edalat F, Sheu I, Manoucheri S, Khademhosseini A. Material strategies for creating artificial cell-instructive niches. Curr Opin Biotechnol. 2012;23(5):820-825.

35. Chung S, King MW. Design concepts and strategies for tissue engineering scaffolds. Biotechnol Appl Biochem. 2011;58(6):423-438.

36. Urbschat A, Obermuller N, Haferkamp A. Biomarkers of kidney injury. Biomarkers. 2011;16 Suppl 1:S22-S30.

37. Elmarakby AA, Sullivan JC. Relationship between oxidative stress and inflammatory cytokines in diabetic nephropathy. Cardiovasc Ther. 2012;30(1):49-59.
38. Cirillo P, Sautin YY, Kanellis J, et al. Systemic inflammation, metabolic syndrome and progressive renal disease. Nephrol Dial Transplant. 2009;24(5):1384-1387.

39. Roh JD, Sawh-Martinez R, Brennan MP, et al. Tissue-engineered vascular grafts transform into mature blood vessels via an inflammationmediated process of vascular remodeling. Proc Natl Acad Sci U S A. 2010;107(10):4669-4674.

40. Ohtsuki K, Hayase M, Akashi K, Kopiwoda S, Strauss HW. Detection of monocyte chemoattractant protein-1 receptor expression in experimental atherosclerotic lesions: an autoradiographic study. Circulation. 2001;104(2):203-208

41. Yadav A, Saini V, Arora S. MCP-1: chemoattractant with a role beyond immunity: a review. Clin Chim Acta. 2010;411(21-22):1570-1579.

42. Deshmane SL, Kremlev S, Amini S, Sawaya BE. Monocyte chemoattractant protein-1 (MCP-1): an overview. J Interferon Cytokine Res. 2009;29(6):313-326.

43. Schrijvers BF, De Vriese AS, Flyvbjerg A. From hyperglycemia to diabetic kidney disease: the role of metabolic, hemodynamic, intracellular factors and growth factors/cytokines. Endocr Rev. 2004;25(6): 971-1010.
International Journal of Nanomedicine

\section{Publish your work in this journal}

The International Journal of Nanomedicine is an international, peerreviewed journal focusing on the application of nanotechnology in diagnostics, therapeutics, and drug delivery systems throughou the biomedical field. This journal is indexed on PubMed Central,

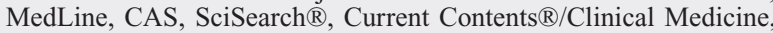

\section{Dovepress}

Journal Citation Reports/Science Edition, EMBase, Scopus and the Elsevier Bibliographic databases. The manuscript management system is completely online and includes a very quick and fair peer-review system, which is all easy to use. Visit http://www.dovepress.com/ testimonials.php to read real quotes from published authors. 